\section{Population Health Management: Coming of Age}

\section{Zander K and Davis T}

President and CEO, the Center for Case Management, USA

\section{Corresponding author: Karen Zander}

\section{Abstract}

The concepts are synergistic in that population management capabilities help to identify high-risk patients, whose costliest episodes can be managed through integrated specialty services, including cardiac and orthopedics that makes better use of post-acute and community-based follow-up. Even in a chronically-ill population, what drive high costs are acute episodes. Bajner believes integrating acute and ACOs could reduce as much as $50 \%$ in high-risk groups.

Keywords: Palliative care; Hospice care; Transitions; Expanded home telemetry; New quality measures

Received: April 03, 2017; Accepted: April 17, 2017; Published: May 30, 2017
Citation: Zander K, Davis T. Population Health Management: Coming of Age. J Hosp Med Manage. 2017, 3:1.

\section{Introduction}

Population Health is finally catching up with itself. Before it was known as Disease Management, it began at New England Medical Center (NEMCH) in Boston, MA (now Tufts Medical Center) more than 30 years ago. At that time, 107 staff nurses were involved in writing outcome-oriented critical paths (CareMap ${ }^{\text {TM }}$ tools) with the attending who specialized in each population-everything from Interleukin Studies to CABG to pediatric scoliosis to embolic stroke (CVA).

For example, if you were a patient who just had a stroke, and you were admitted to the ED, you would have Paul Duggan as your care-giver RN. If he wasn't on duty, you would have another ED nurse following Dr. Kaplan's critical path/CareMap ${ }^{\text {TM }}$ for an embolic stroke.

If you then went to our neuro-ICU, you would have Barbara Wilkoren as your care-giver RN. If you progressed to the Neuro Unit, you would have Laurie Luke taking care of you. If you went to our rehab unit, you would have Katie Hanlon, and if you need our Coumadin Clinic, you would meet with Trish Chudkowsky. They all met together weekly to review their 25 or so stroke patients somewhere in the system (inpatient or outpatient) and talk with each other about how interventions could be improved and how patients were doing-invaluable. In fact, their nurse manager covered their patients so they could attend this meeting. Every 3 months the group met with Dr. Kaplan and went over what little statistics we had at the time. Because of my interest in Population Health, I was asked to consult at Arnot Ogden Medical Center in Elmira, NY.

Following is their story about their Programs of Care: Governing
Clinical Practice across Time and Place: What would you as an administrator give to have the whole organization at all levels working together to improve the outcomes of patient care, not only inside but outside of your walls? Have you been struggling with fragmented services, turf issues, and other barriers that prevent all the disciplines working together for the patient? Have you been searching for a positive way to include community, physicians and agencies in the overall plan? A major restructuring utilizing the Programs of Care also known as self-managing teams will move your organization in a direction that reduces silos and improves outcomes for your patients.

Definition and Purpose: Programs of Care, also known as collaborative practice groups or self managing teams, are permanent interdisciplinary teams brought together to focus on the care provided for a specific patient population. The focus can be within or outside the organization, or both, based on the need of the population of patients being evaluated. The scope seems very global but the teams can and do look at the structure, process and outcomes of patient care across the levels of care and for extended timeframes into recovery. Their work may include reviewing and revising a single small task to solve a problem or development of a large program design such as development of clinical pathways and or orders sets.

The functions of Programs of Care in an organization can include;

1. Standardization of practice,

2. Evaluation of the continuum of care,

3. Quality Improvement, 
4. Evaluation of the flow of patients through the system,

5. Evaluation of care given,

6. Evaluation of data (Core measures and HQI data included),

7. Implementation of interventions to affect the outcomes of care,

8. Clinical pathway development and monitoring,

9. Use of evidence-based medicine.

The role of these groups should be organized around measurable goals based on data. This gets the groups focused on specific issues that can be addressed immediately. These first tasks get the groups up and moving fast and developing as a team around their accomplishments.

Structure: There are 5 main roles:

1. Program of Care Direction/oversight,

2. MD Co-leader,

3. Non MD Co-leader,

4. Administrative Facilitator,

5. Member.

The structure is paradoxically simple and complex. Oversight and coordination is managed by someone who has the vision of the programs of care to bring to all the groups. In our organization that is the Sr. Director Continuum of Care who also directs the acute- care case management service. Consistency of vision is of utmost importance in organizations which are under a great deal of change. Having one person as a constant for these groups is imperative.

The Leadership of each Program of Care is dual in nature and provided by clinical experts. One leader of each group is a physician who cares for and knows the population of patients well. This role appeals to the physicians because they have always been the leader of patient care and now they are in a forum where they can educate and foster good care for their patients. Most physicians love it. The second leader is a staff clinical expert who cares for these patients daily and engages the staff in evaluating the care they and their co-workers render. This is a powerful way to engage the bedside staff in outcomes of care. We have at this point engaged the medical staff in partnership with the clinical experts at the bedside. For example: In the Pneumonia/COPD POC the Physician Leader is a pulmonologist and the clinical lead is a staff nurse from the ICU. This group is facilitated by the Sr. Director of Nursing and membership includes respiratory therapy, education, infection control, ED nursing, and many other staff members. This group has seen to the success of our Pneumonia care provided in the organization. Having reached the $2^{\text {nd }}$ and $1^{\text {st }}$ decile for this group of patients Facilitation comes from upper level management. In our case the AVP's and VP's took the role of facilitator, sending a message to the organization about the importance of the structure. This arrangement also gets to the financial piece right away. When there are discussions about the need for money to buy something we have someone at the table that can say right now whether money is available or not.
Membership depends on the diagnosis group that the team is working on. The membership should be inclusive with as many physicians as possible. Membership by physicians can be enhanced by supporting their leadership role with the partnership leader model. The facilitator makes sure the minutes are done and sent and the second leader does a lot of the grunt work which the physicians don't like to spend time with. Identifying a time and place that is best for the physicians helps attendance. Once they attend they see the importance of their leadership for the group and the patient focus of the projects which appeals to them a great deal. At that point they are engaged and they continue to be so. We started out with the 2 year contract but many physicians and members have been on the teams for 4 years because they don't want to give up their projects.

Agenda: The responsibility for the programs of care is to be the oversight of care and anything that involves. They truly are the forum where care decisions are made and disseminated through the organization based on researched practice guidelines. For example:

The Programs of Care have become the primary infrastructure to:

1. Review the practice structure inside and outside the organization,

2. Identify areas that need improvement based on data,

3. Making recommendations to the organization and physicians for changes in practice or system changes as appropriate,

4. Review and put into practice the current guidelines, order sets, and clinical pathways for patient care,

5. Monitor the changes in practice,

6. Data analysis,

7. Quality improvement,

8. Sentinel event review,

9. Meeting regulatory requirements for a specific group of patients (Core measures, HQI, QIO, JACHO),

10. Monitoring the financial impact of care as it is provided for the group of patients they are monitoring,

11. Education of the caregivers, facility and community about core measures and the changes recommended.

How to get started: Start with an administrative steering committee.

1. Identify the diagnosis groups the organization wants to impact,

2. Identify the oversight person,

3. Identify the data group or person,

4. Sit down with the leadership and facilitator of each group first,

5. Get the groups together and educate them about the process,

6. Get started.

How to keep going: Staying focused comes from the central 
person who maintains the vision and visits each team to assess forward progress. This oversight person meets with the facilitators regularly to discuss progress and barriers in the system to forward progress. This facilitator group brainstorms how to remove the barriers and support the teams in their mission.

\section{Case Study}

The Cancer POC was brought together to review the care of cancer patients provided in the community. We focused first on the care of the breast patient. There was a concern that the patient who had an abnormal mammogram was not managed to their best benefit. The process from abnormal mammogram through diagnosis and treatment was reviewed and many changes were made. One such change was the process of the sentinel node biopsy. We found we were finding the sentinel node $10 \%$ of the time. We looked at the process and included the Surgeons, the OR, and the Lab, the pathologist, the oncologist and anyone else who had a hand in the process. We totally changed our process and some equipment and were able to increase our rate of finding the sentinel node to $90 \%$. Results like that speak to the clinicians on the team in a way that no other quality improvement process has.

\section{Summary}

The benefit to the organization is a strong focus on patients and the care they receive. The movement of organizations and the practice within and outside the walls has struggled with outcomes and the measurement of outcomes. By concentrating on patient outcomes the care we give becomes outcome focused care. This moves the organization in the direction the JACHO and CMS has been attempting to move us by force. By looking at the care we provide these teams automatically start to measure outcomes. These teams become the central repository of data and by virtue of the role they have in care management develop responses to the data, by they are following the QI process of continuous quality improvement.

Programs of Care extended to every patient population go beyond task forces, service lines, and six sigma methods by producing a permanently aligned structure for the governance of clinical practice. As such they are not standards for process problems, but rather standard bearers in a continuously renewed culture [1]

\section{PACE: Program of All-Inclusive Care for the Elderly}

The Programs of All-Inclusive Care for the Elderly (PACE) provides comprehensive medical and social services to certain frail, community-dwelling elderly individuals, most of whom are dually eligible for Medicare and Medicaid benefits. The PACE program has been in existence a long time. An interdisciplinary team of health professionals provides PACE participants with coordinated care. For most participants, the comprehensive service package enables them to remain in the community rather than receive care in a nursing home. Financing for the program is capped, which allows providers to deliver all services participants need rather than only those reimbursable under Medicare and Medicaid feefor-service plans. PACE is a program under Medicare, and states can elect to provide PACE services to Medicaid beneficiaries as an optional Medicaid benefit. The PACE program becomes the sole source of Medicaid and Medicare benefits for PACE participants.

Financing for the program is capped, which allows providers to deliver all services participants need rather than limit them to those reimbursable under Medicare and Medicaid fee-forservice plans. The PACE model of care is established as a provider in the Medicare program and as enables states to provide PACE services to Medicaid beneficiaries as state option. The PACE program becomes the sole source of services for Medicare and Medicaid eligible enrollees. Individuals can leave the program at any time.

\section{PACE eligibility}

Individuals can join PACE if they meet certain conditions:

- Age 55 or older,

- Live in the service area of a PACE organization,

- Eligible for nursing home care,

- Be able to live safely in the community.

PACE program becomes the sole source of services for Medicare and Medicaid eligible enrollees. Individuals can leave the program at any time (Figure 1).

Case management and population health/Disease management: Case Management with the help of MSW Social Workers is the engine that makes Population Health work. "From a medical case management perspective, disease management can be defined as an information-intensive series of clinical processes and services across the continuum of health care that identifies the medically at-risk population and professionally manages patients in a manner that improves care, promotes wellness, and manages/reduces cost" [2]. This is basically the definition of case management/care coordination! As early as the late 1800's police identified people in need of food, clothing, and shelter, and women founded charities to meet the need (Table 1).

"...the current concept of disease management first emerged in 1991 as a strategic response by the pharmaceutical industry to marketplace forces and the evolution of HMOs into managed care organization (MCOs) and other forms of more proactive integrated care that have the potential to help maintain quality in an increasingly price-sensitive environment. Historically, case managers have always strived to manage illness through a collaborative approaches aimed at the delivery of high-quality, cost-effective health care. However, this early form of disease management was implemented primarily ...episodic, componentbased delivery system. The increased sophistication, availability, and acceptance of clinical practice guidelines also promise to enhance the ability of case managers to provide true-patientcentered care and wellness management" [3].

The process of case management classically follows a pattern:

- Step 1: Identify at-risk members of the insurance plan, managed care plan, elderly, etc., using criteria, 


\section{How Ranking of Impact/Significance of Six Focus Areas in Avoiding ED/Hospital Use}

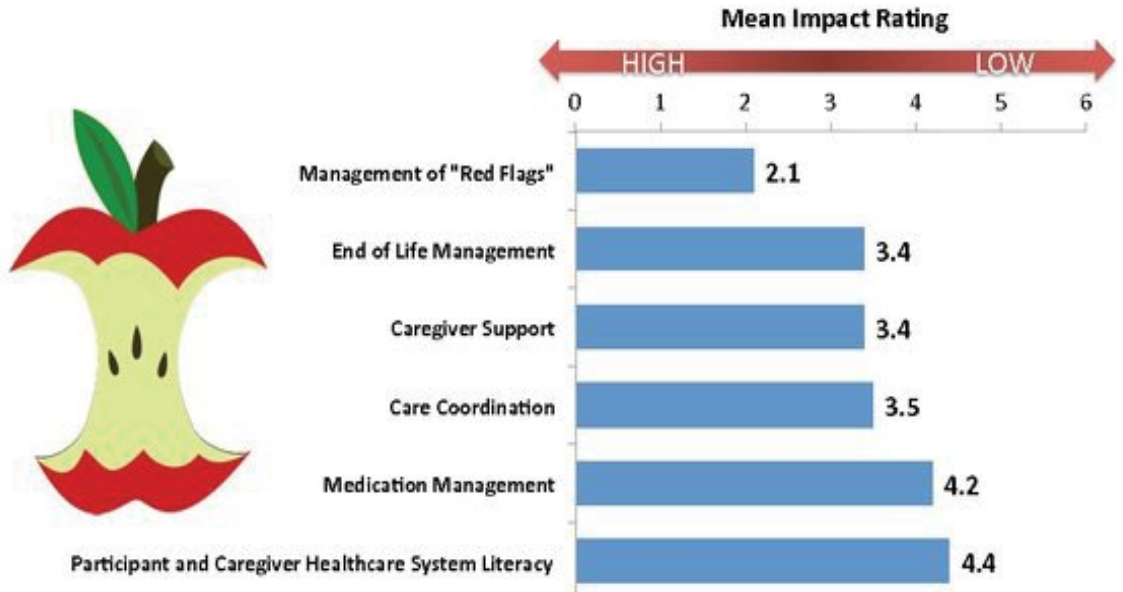

Stefanacci RG, Reich S, Casiano, A. Application of PACE Principles for Population Health Management of Frail Older Adults. Population Health Management. 2015 Oct;18(5):367-72.

Figure 1 Ranking impact on hospital use.

Table 1 Competencies in disease management.

\begin{tabular}{|c|c|c|c|}
\hline & Cognitive Knowledge & Psychomotor Skill & Values/Beliefs \\
\hline $\begin{array}{l}\text { Introductory } \\
\text { (Learning; focus on } \\
\text { "Me" and the "Task") }\end{array}$ & $\begin{array}{l}\text { Defines, describes } \\
\text { 1.Defines disease management within } \\
\text { the continuum of care } \\
\text { 2.Reviews HIPAA policies, Patient Bill } \\
\text { of Rights and consent forms } \\
\text { 3.Learns and uses computer skills }\end{array}$ & $\begin{array}{l}\text { Perception } \\
\text { 1.Shadows experienced DM staff } \\
\text { 2.Discusses data related to } \\
\text { organization's target population } \\
\text { 3.Describes disease-specific programs } \\
\text { that the organization sponsors [16] }\end{array}$ & $\begin{array}{l}\text { Receives, listens } \\
\text { 1.Actively listens to patients and co- } \\
\text { workers } \\
\text { 2.Is receptive to the input of others, } \\
\text { including alternative ways of doing things } \\
\text { 3.Treats each patient's history and current } \\
\text { condition with confidentiality and respect }\end{array}$ \\
\hline $\begin{array}{l}\text { Familiarization } \\
\text { (Rehearsing; focus } \\
\text { on the patient and } \\
\text { information) [17] }\end{array}$ & $\begin{array}{l}\text { Comprehends } \\
\text { 1.Understands the disease pathology, } \\
\text { associated pharmacology and standard } \\
\text { treatment of the disease being } \\
\text { managed } \\
\text { 2.States how DM could enhance } \\
\text { patient autonomy, reduce } \\
\text { complications and appropriately utilize } \\
\text { services } \\
\text { 3.Identify ways that the DM program } \\
\text { meets organization's needs beyond CC } \\
\text { and DP. } \\
\text { 4.Explain concepts related to patient's } \\
\text { readiness to change }{ }^{1} \\
\text { 5.Identifies trends within the patient } \\
\text { population being managed. } \\
\text { 6.Describes Motivational Interviewing } \\
\text { and how the techniques enhance DM } \\
\text { interventions }{ }^{2}\end{array}$ & $\begin{array}{l}\text { Guided response } \\
\text { 1.Works with preceptor to carry } \\
\text { out DM program and patient } \\
\text { communications } \\
\text { 2.Identifies patient readiness to } \\
\text { change. } \\
\text { 3.Recognizes patient's educational } \\
\text { level, comorbidities, status of } \\
\text { condition and social network. } \\
\text { 4.Develops realistic short and long } \\
\text { term goals with the patient } \\
\text { 5.Enrolls patient in appropriate } \\
\text { programs according to criteria } \\
\text { 6.Practice Motivational Interviewing }\end{array}$ & $\begin{array}{l}\text { Responds, questions } \\
\text { 1.Reflects positive and energetic attitude } \\
\text { 2.Enjoys patient educator role } \\
\text { 3.Take opportunities for education and } \\
\text { self-management } \\
\text { 4.Imagines self in patient's situation } \\
\text { 5.Communicates teamwork, caring and } \\
\text { compassion }\end{array}$ \\
\hline
\end{tabular}




\begin{tabular}{|c|c|c|c|}
\hline \multirow{9}{*}{$\begin{array}{l}\text { Proficiency } \\
\text { (Mastery in } \\
\text { Complexity, } \\
\text { precepting; focus on } \\
\text { others) }\end{array}$} & Analyses & Complex, overt actions & Evaluates \\
\hline & \multirow{2}{*}{$\begin{array}{l}\text { 1.Analyzes the impact of patient } \\
\text { comorbidities and designs patient } \\
\text { specific DM plans }\end{array}$} & \multirow{2}{*}{$\begin{array}{l}\text { 1.Strategically uses education and } \\
\text { negotiation to enhance DM program } \\
\text { compliance }\end{array}$} & 1.Is proactive and takes initiative \\
\hline & & & 2.Accepts accountability for results, does not \\
\hline & $\begin{array}{l}\text { 2.Identifies the patient impact of } \\
\text { community changes on DM plan }\end{array}$ & $\begin{array}{l}\text { 2.Serves as a dedicated preceptor } \\
\text { with successful results }\end{array}$ & $\begin{array}{l}\text { 3.Values initiatives from public health and } \\
\text { other sectors }\end{array}$ \\
\hline & $\begin{array}{l}\text { 3.Makes sound suggestions about } \\
\text { program improvements }\end{array}$ & $\begin{array}{l}\text { 3.Utilizes all system available } \\
\text { to assist current and potential }\end{array}$ & $\begin{array}{l}\text { 4.Explores professional certification } \\
\text { opportunities }\end{array}$ \\
\hline & 4.Introduces alternative solutions & $\begin{array}{l}\text { participants in performance } \\
\text { improvement }\end{array}$ & \\
\hline & presentations & 4.Performs data collection and & \\
\hline & 5.Stays current with national & calculates outcome data & \\
\hline & $\begin{array}{l}\text { standards identified by employer and } \\
\text { uses them as benchmarks }\end{array}$ & $\begin{array}{l}\text { 5.Links outcomes data to population } \\
\text { based trends }\end{array}$ & \\
\hline \multirow{4}{*}{$\begin{array}{l}\text { Excellence } \\
\text { (Leading change; } \\
\text { focus on larger } \\
\text { system) }\end{array}$} & Synthesizes & Adapts & Reorganizes usefully \\
\hline & \multirow{3}{*}{$\begin{array}{l}\text { 1.Synthesizes new ideas and current } \\
\text { research into potential program - } \\
\text { changes } \\
\text { 2.Informally researches alternative } \\
\text { therapies, business models, patient } \\
\text { educational methods, web-based } \\
\text { applications }\end{array}$} & $\begin{array}{l}\text { 1.Leads performance improvement } \\
\text { groups within organization }\end{array}$ & $\begin{array}{l}\text { 1.Articulates the value of strategic change by } \\
\text { giving examples and encouraging others }\end{array}$ \\
\hline & & 2.Maintains effective relationships & 2.Advocates for healthy communities at the \\
\hline & & $\begin{array}{l}\text { with community providers to } \\
\text { enhance patient access and } \\
\text { outcomes }\end{array}$ & level external to the organization \\
\hline Innovation/ & Experiments, researches & Invents, creates & Value Maturity \\
\hline \multirow{2}{*}{$\begin{array}{l}\text { Discovery } \\
\text { (Creating; focus } \\
\text { on the "greater } \\
\text { good" and greater } \\
\text { functionality) }\end{array}$} & $\begin{array}{l}\text { 1.Synthesize "lessons learned" and } \\
\text { conceptually stretches them to new } \\
\text { applications to resolve problems }\end{array}$ & $\begin{array}{l}\text { 1.Develop new DM programs or tools } \\
\text { to meet the needs of the patient and } \\
\text { organization }\end{array}$ & \multirow[t]{2}{*}{$\begin{array}{l}\text { 1.Inspires others and promotes participation } \\
\text { in new approaches. }\end{array}$} \\
\hline & $\begin{array}{l}\text { 2.Formally researches alternative } \\
\text { therapies, business models, patient } \\
\text { education approaches and web-based } \\
\text { applications }\end{array}$ & $\begin{array}{l}\text { 2.Conducts research or major change } \\
\text { projects }\end{array}$ & \\
\hline
\end{tabular}

- Step 2: Provide in-depth assessment of each person,

- Step 3: Determine the benefits of the at-risk populations, whether fee-for-service Medicare, etc.

- Step 4: Develop an individual care plan for each person and their family(if involved), which might extend for 90 days if the patients is part of a Bundled Payment risk contract,

- Step 5: Follow the plan and coordinate the team around the plan,

- Step 6: Keep data -both outcome and financial--and measure the results in the categories of Health (physiological and mental), Function (role, work, mobility), Absence of Complications typical to the diagnosis or co-morbidities, and Knowledge in measureable terms [4].

Care Coordination; aka Case Management has been defined by the AHRQ (after reviewing 40 definitions) as "Care coordination is the deliberate organization of patient care activities between two or more participants (including the patient) involved in a patient's care to facilitate the appropriate delivery of health care services. Organizing care involved the marshaling of personnel and other resources needed to carry out all required patient care activities and is often managed by the exchange of information among participants responsible for different aspects of care" [5].

\section{Three different perspectives:}

1. Patient/family: "Patient, their families, and other informal caregivers experience failures in coordination particularly at points of transition. Transitions may occur between health care entities, and over time and are characterized by shifts in responsibility and information flow. Patients perceive failures in terms of unreasonable levels of effort required on the part of themselves or their informal caregivers in order to meet care needs during transitions."

2. Health care Professionals: "Patient and family-centered team-based activity designed to assess and meet the needs of patients, while helping them navigate effectively and efficiently through the health care system. Clinical coordination involves determining where to send the patient next (sequencing among specialists), what information about the patient is necessary to transfer among health care entities, and how accountability and responsibility is managed among all health care professionals. Care coordination addresses potential gaps in meeting patient's interrelated medical, social, developmental, behavioral, education, informal support system, and financial needs in order to achieve optimal health, wellness, or end-of-life outcomes, according to patient preferences." 
3. System Representative: "The goal is to facilitate the appropriate and efficient delivery of health care services both within and across systems." P. 5.

- The Effect of CMS's Readmission Penalties and Bundled Payments on Case Management,

- Fragmented health care services by separating patients deemed at high risk for readmission (using one of 4 tools: LACE, 8 Ps from the Society of Hospital Medicine, The Vulnerable Elderly Survey, and a modified Charleson Comorbidity scale.

- "Case managers are the most crucial elements of an effective PHM team, reported $64 \%$ of respondents, slightly edging out PCPs (60\%) and health coaches (55\%)" [6].

- In population health management, populations are assessed and then segmented across the spectrum of health risk: from Healthy to At Risk to Chronic to Catastrophic and the true cost savings result from continually moving patients down the risk scale [7].

In the same article, Curran lists the 4 I's of a successful PHM program:

1) Information,

2) Incentives to motivate behavior at the employer level and the population level, such as passes to gyms, Weight Watchers, completing the Health Risk Assessment, etc.

3) Infrastructure of resources, services, and tools,

4) Imperative for technology: personalized messaging and calling, dashboards for tracking progress, mobile phones and tablets, such as provided by CarePort ${ }^{\mathrm{TM}}$, RoundingWell ${ }^{\mathrm{TM}}$ and RelnforcedCare $^{\mathrm{TM}}$.

"Hospitals and health systems face any number of challenges in managing the health of a population. Most important, perhaps, is putting in place a successful population health strategy and changing a health care organization's culture to one that embraces the Triple Aim as a core tenet. Leaders must have a clear vision and be collaborative, empowering, innovative and tolerant of failure. They, along with their teams, must also learn what creates success and brings value to their communities, networks and organizations. Organizations move toward population health, the ones that will be successful will be the ones with clarity of vision, a dedication to innovation and change, a commitment to the consumer, and the ability to confront the brutal facts with relentless optimism and focus" [8].

In an article by Lola Butcher about Consumer Segmentation hitting health care, she writes that it can lead to better care management. "Carolinas HealthCare System, operating in more than 900 locations throughout North and South Carolina, is using an entirely different approach to segment its patients.

Avery Ashby, assistant vice president at the health system's Dickson Advanced Analytics group, leads a population health analytics team of data scientists, statisticians, business intelligence specialists, epidemiologists and others. Using data from a three-year period, he and his colleagues have segmented

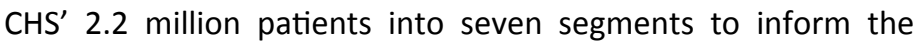
health system's care management strategy.

"We are getting ahead of the curve to make sure we have the infrastructure to be attractive to those commercial payers that may want additional care management services that for so long they have had to provide on their own," Ashby says.

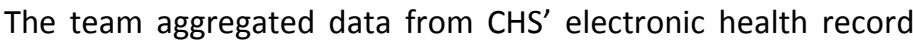
system and its billing system supplemented with behavior, consumer and geospatial data that identify the census tract in which each patient lives. Instead of segmenting patients by cost or diagnosis, the analysts used a sophisticated hierarchical cluster analysis to "let the data talk for itself," as Ashby puts it.

That means that the team was not looking for a certain number of segments or trying to sort patients by a set of preconceived assumptions. Rather, the analytical techniques sorted all patients into seven mutually exclusive groups. In six of those groups, patients "clustered" together because of traits they shared:

\section{Advanced cancer}

These patients, who account for 0.6 percent of $\mathrm{CHS}^{\prime}$ patient population, clustered together on the basis of their high billed charges (a proxy for resource utilization) and cancer diagnoses. (Patients with less serious or less costly cancer diagnoses may not fit into this group because they are more similar to the clinical characteristics in another segment.)

\section{Complex chronic}

These patients - typically older, low-income, covered by Medicare, widowed, and struggling with behavioral health problems and multiple chronic conditions - account for 6.6 percent of the patient population.

\section{Aging rising risk}

Younger than patients in the "complex chronic" segment, these people typically are married, commercially insured and have just one chronic condition, such as Type 2 diabetes, that is under control. They make up 16.7 percent of the patient population.

Mental health: A large percentage of patients have a mental health diagnosis, of course, but the 0.1 percent who clustered to create this segment shares some specific commonalities. They are older teens and young adults, most of whom are male, who have serious mental health conditions that require a great deal of support.

\section{Pregnancies and deliveries}

These healthy women make up 2.6 percent of the system's patients.

\section{Newborns and toddlers}

In general, these are healthy children under age 3 who account for 2.5 percent of $\mathrm{CHS}^{\prime}$ patients.

Together, the patients in the first four segments make up 24 percent of $\mathrm{CHS}^{\prime}$ patients - and 76 percent of billed_charges. The 
seventh segment - dubbed "sparse information, acute and well" - accounts for 70.8 percent of patients and only 17.4 percent of charges.

That segmentation allows for care management protocols that target specific slices of the patient population. For example, CHS knows that around 145,000 patients fall into the "complex chronic" segment, which is the second most expensive segment. That's an unmanageable number, Ashby says. But having so much data about those patients in an enterprise data warehouse lets the analysts identify subsets - for example, those complex chronic patients who have increasing year-over-year charges, have a certain combination of diagnoses, have had avoidable utilization and belong to certain demographics - that warrant specific attention.[9]"

In another powerful example of population health management, Cambridge Health Alliance ( $\mathrm{CHA})$, an Accountable Care Organization in 3 neighborhoods, although headquartered in Cambridge, MA is using analytics to identify hi dollar patients in combination with high need patients and families. They have 5 principles the program is founded on:

1. Care management is not the goal: clinical integration toward realistic outcomes to which all parties can commit is the goal

2. One title across settings: Care Management,

3. One care manager/"conductor",

4. One plan of care across time and place,

5. Patient/family version of plan-calendar and pictures,

6. Family is the "other" patient,

7. Two "Hubs" are PCMH and ED.

" $\mathrm{CHA}$ has found that the best ACO strategy for them is aiming at identifying and engaging patients whose complex and complicated care needs cannot be addressed by the health care system as currently designed. They have learned that symptoms of a poor condition are under, over-utilization, or misutilization of the delivery system, frequent ED visits, inpatient stays and readmissions, poor health outcomes, unengaged/ unsatisfactory relationships with providers and staff, and poor self-management of comorbidities which results in low "value" care." They have found that the top $5-10 \%$ of patients require about $50 \%$ of the team's time. Their care management teams include 2 professionals along with the community health worker [10]:

\section{Social work care manager}

\section{Care plan development:}

- Address systemic barriers to care,

- Integrate care among various providers, especially Behavioral Health providers,

- Assess substance abuse and mental health needs and assess patient readiness of change,
- Address anxiety and trust issues,

- Coach about behavior change.

\section{Community health worker:}

- Meet with patient (and family if available) during hospitalization,

- Arrange for post-acute home visit and other home visits as needed,

- Appointment reminders and accompaniment,

- Arrange transportation,

- Arrange entitlements,

- Link to community resources,

- Teach patient self-monitoring strategies.

RN care manager:

- Care plan development,

- Integrate care among various providers,

- Assess degree of support required for COPD, diabetes, etc.

- Arrange for nutrition, pulmonary consults, etc.

- Coach patients about medication adherence and self-care strategies,

- Arrange for VNA and other services,

The organizing concept of the CHA population health program is based on the following (Figure 2).

They utilize community health workers for issues such as casefinding, transportation arrangements, and food stamps that professionals are not needed for. They do use data from health plans to identify the most expensive patients. CHA also asks the primary care physicians if they expect to see this patient in the hospital in the next 6 months and why. The case managers in the program focus on the "rising risk" patients, which in a publication from IBM states that [11]:

- $40-60 \%$ are healthy,

- $20-25 \%$ are at risk,

- $5-15 \%$ have multiple chronic conditions,

- $2-3 \%$ are catastrophically ill.

In that same text, the complete approach to population health is listed as [12]:

- Data a knowledge driven,

- Every person has a plan,

- Automation to manage a population down to the individual,

- Team-based care.

"Atrius Health, another Massachusetts-based ACO, has 675 adult and pediatric patients, including 52,000 Medicare beneficiaries. $75 \%$ of the revenue is risk-based. Atrius owns a corporate data 


\section{Primary care and}

Prevention:

Medical and OB

Populations F

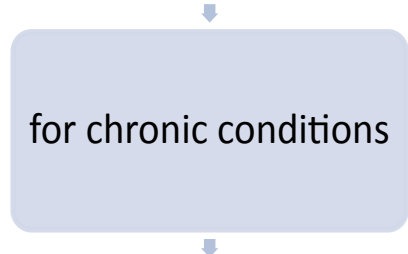

Tertiary Care
Primary Care and

Prevention:

Psychiatric/Behaviora I Health Population

$\sqrt{6}$

Secondary Prevention/Care for chronic conditions

\section{$\sqrt{1}$}

\section{Tertiary Care}

Figure 2 Organizing concept of the CHA population health program.

warehouse and integrates with multi-payer claims data. They own Level 3 PCMHs, and spend time identifying clinical gaps and gaps in coordination, engaging clinical leaders in fixing the gaps. They also study program design, develop tools, implementation of the program and tools, track and measure, and perform Continuous Quality Improvement. According to Rick Lopez, Director of multispecialty and the VNA Care Network, $2 \%$ of the focus is on end of life/Advanced Illness management, tight control is on $3 \%$ of the population, $15 \%$ of the resources are spent on chronic illness. Their 2015 focus, which resulted in a 2 day reduction in LOS and lowering their readmission rate by $2 \%$, was" [13]:

- Providing MD and NP teams on site at $1 / 3$ of their preferred SNFs. They have no contracts with these SNFs, but a list of joint expectations.

- Palliative care/hospice,

- Care Transitions,

- COPD,

- Expanded home telemetry,

- New quality measures,

- Develop a SNF PPO.

\section{Conclusion}

In summary: "The concepts are synergistic in that population management capabilities help to identify high-risk patients, whose costliest episodes can be managed through integrated specialty services, including cardiac and orthopedics, that make better use of post-acute and community-based follow-up (Appendix). Even in a chronically-ill population, what drives high costs are acute episodes. Bajner believes integrating acute and ACOs could reduce as much as 50\% in high-risk groups" [14-16] (Figure 3).

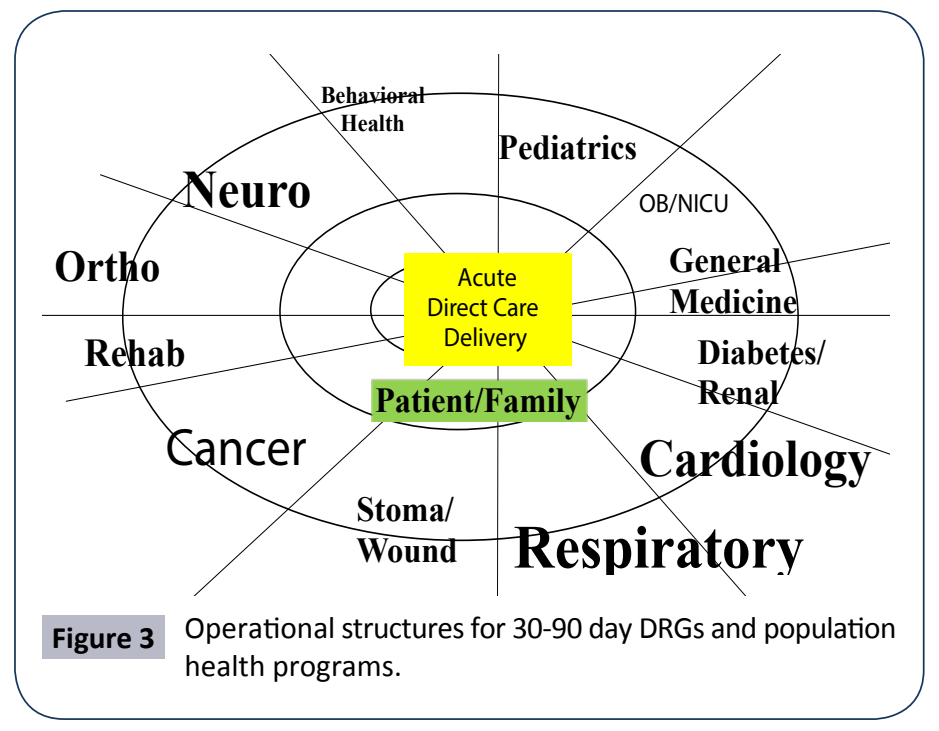




\section{References}

1 Zander K (2005) Icy Blu II - 2003 International 9900ix. Overdrive staff news.

2 Ward, Marcia, RN, Rieve JRN (1997) The Role of Case Management in Disease Management. In Todd Warren and Nash David (eds.) Disease Management: A Systems Approach to Improving Patient Outcomes. American Hospital Publishing, Inc.

3 IBID, Wikipedia.

4 Structure of original CareMap ${ }^{\mathrm{TM}}$ tools, provided by CCM.

5 McDonald KM, Schultz E, Albin L, Pineda N, Lonhart J, et al. (2010) Care Coordination Measures Atlas. Department of Health and Human Services, USA.

6 Seagirt NJ (2013) Health Intelligence Network Guide to Population Health Management, pp: 1-11.

7 Curran P (2013) Profiting from Population Health Management: Applying Analytics in Accountable Care. Seagirt, NJ; Health Intelligence Network, pp: 2-3.
8 Byrne E, Smith J (2016) The New Keys to Population Health Management. HHN Daily.

9 Betcher L (2016) Consumer Segmentation Has Hit Health Care. Here's How it Works, HHN Daily.

10 Carr E (2014) Slides from Care Coordination Summit.

11 IBM Watson Health (2015) Population Health Management: Confidence and control in a complex time;

12 Lopez R (2015) Population Health webinar.

13 Bajner R (2014) Director of Provider and Payer Practice, Navigant. In Larkin $\mathrm{H}$ (ed.) Lessons for Hospitals Transitioning to Population Health Management.

14 HCPro (2009) (C) CCM, In Competency Tools for Case Management Professionals.

15 Prochaska JO, DiClemente CC as described In Llewellyn, L.

16 Rollinick S, Miller W (1995) What is Motivational Interviewing? Behavioral and Cognitive Psychotherapy 23: 325. 